\title{
Sulfation of Betulin
}

\section{with Chlorosulfonic Acid in Pyridine}

\author{
Natalia Yu. Vasilyeva, Alexander S. Kazachenko, \\ Yuriy N. Malyar and Boris N. Kuznetsov* \\ Institute of Chemistry and Chemical Technology SB RAS \\ FRC "Krasnoyarsk Science Center SB RAS" \\ Krasnoyarsk, Russian Federation \\ Siberian Federal University \\ Krasnoyarsk, Russian Federation
}

Received 15.06.2020, received in revised form 23.07.2020, accepted 14.08.2020

\begin{abstract}
It was found that when betulin is sulfated with chlorosulfonic acid in pyridine medium, 3,28-disulfate of betulin is formed in a stable salt form. Under optimal synthesis conditions: temperature $70^{\circ} \mathrm{C}$, duration 2 hours, molar ratio betulin / chlorosulfonic acid 4.0, betulin is completely converted into betulin 3.28-disulfate. The structure and composition of betulin 3,28-disulfate were confirmed by elemental analysis, IR, Raman and 13C NMR spectroscopy. Betulin 3,28-disulfate was isolated both in the form of an unstable $\mathrm{H}+$-form and in a stable forms of sodium and pyridinium salts. Sodium salt of 3,28-disulfate is a needle-like crystals collected in cobweb-like aggregates. The sodium salt of 3,28-disulfate has mycellar properties, the critical concentration of mycellar formation is $0.23 \mathrm{mmol} / \mathrm{L}$.
\end{abstract}

Keywords: betulin, sulfation, chlorosulfonic acid, pyridine, betulin 3,28-disulfate, identification IR-, Raman- and ${ }^{13} \mathrm{C}$ NMR-spectroscopy, scanning electron microscopy, thin-layer chromatography, micelle formation.

Citation: Vasilyeva N.Yu., Kazachenko A.S., Malyar Yu.N., Kuznetsov B.N. Sulfation of betulin with chlorosulfonic acid in pyridine, J. Sib. Fed. Univ. Chem., 2020, 13(3), 447-459. DOI: 10.17516/1998-2836-0197

(C) Siberian Federal University. All rights reserved

This work is licensed under a Creative Commons Attribution-NonCommercial 4.0 International License (CC BY-NC 4.0).

* Corresponding author E-mail address: inm@icct.ru 


\title{
Сульфатирование бетулина хлорсульфоновой кислотой В пиридине
}

\author{
Н.Ю. Васильева, А.С. Казаченко, \\ Ю.Н. Маляр, Б.Н. Кузнецов \\ Институт химии и химической технологии СО РАН \\ ФИЦ «Красноярский научный центр СО РАН» \\ Российская Федерация, Красноярск \\ Сибирский федеральный университет \\ Российская Федерачия, Красноярск
}

Аннотация. Установлено, что при сульфатировании бетулина хлорсульфоновой кислотой в среде пиридина образуется 3,28-дисульфат бетулина в стабильной солевой форме. При оптимальных условиях синтеза: температура $70{ }^{\circ} \mathrm{C}$, продолжительность 2 ч, мольное соотношение бетулин/хлорсульфоновая кислота 1:4 бетулин полностью превращается в 3,28-дисульфат бетулина. Строение и состав 3,28-дисульфата бетулина подтверждены данными элементного анализа, ИК-, КР- и ЯМР 13С-спектроскопии. 3,28-Дисульфат бетулина выделен как в виде малостабильной $\mathrm{H+-формы,} \mathrm{так} \mathrm{и} \mathrm{в} \mathrm{стабильной} \mathrm{форме} \mathrm{в} \mathrm{виде}$ натриевой и пиридиниевой солей. Натриевая соль 3,28-дисульфата представляет собой игольчатые кристаллы, собранные в агрегаты паутинообразной формы. Натриевая соль 3,28-дисульфата обладает мицеллярными свойствами, значение критической концентрации мицеллообразования составляет 0,23 ммоль/л.

Ключевые слова: бетулин, сульфатирование, хлорсульфоновая кислота, пиридин, 3,28-дисульфат бетулина, идентификация ИК-, КР- и ${ }^{13} \mathrm{C}$ ЯМР-спектроскопией, растровая электронная микроскопия, тонкослойная хроматография, мицеллообразование.

Цитирование: Васильева, Н.Ю. Сульфатирование бетулина хлорсульфоновой кислотой в пиридине / Н.Ю. Васильева, А.С. Казаченко, Ю.Н. Маляр, Б.Н. Кузнецов // Журн. Сиб. федер. ун-та. Химия, 2020. 13(3). С. 447459. DOI: $10.17516 / 1998-2836-0197$

\section{Введение}

Тритерпеновые соединения являются важнейшим классом биологически активных веществ, потенциальных фармацевтических активных субстанций, лекарственных препаратов и фитопрепаратов [1-7]. Особое место в ряду тритерпеноидов занимают пентациклические тритерпеноиды лупанового ряда - производные бетулина и бетулиновой кислоты. Бетулин (lup-20(29)-en-3ß,28-dio) может быть легко получен из более чем двухсот видов растений, хотя самым богатым источником бетулина считают семейство Betulaceae, особенно Betula alba, Betula pubescens, Betula platyphylla и Betula pendula [2-4]. Содержание бетулина во внешней части коры березы варьирует в пределах 10-35\% в зависимости от вида березы, места и условий ее произрастания, возраста дерева и других факторов [5]. Канадским ученым также удалось 
получить 56\% бетулина в экстракте желтой бересты [4]. В экспериментах in vitro и in vivo бетулин, его сопутствующие аналоги, бетулиновая кислота и другие производные бетулина демонстрируют противовоспалительные, противосудорожные, антибактериальные, противовирусные, противоопухолевые, высокую анти-ВИЧ-активность, органопротекторные и другие виды биологической активности [2-10].

Доступность и биологическая активность бетулина ставят его в ряд ценных природных источников для использования как в нативном состоянии, так и в виде различных продуктов трансформации. Однако его низкая растворимость в воде ограничивает применение препарата в медицине, косметике и других областях. Для изучения растворимости в воде тритерпеноидов лупанового ряда используют различные методы: солеобразование, применение специальных лекарственных форм, позволяющих обеспечить векторную доставку труднорастворимых соединений, нано- и биотехнологические приемы улучшения растворимости $[3,6,8,10]$. Улучшение растворимости тритерпеноидов, как и любых гидрофобных лекарственных веществ, может быть достигнуто путем их химической модификации. Растворимость и биодоступность тритерпеноидов могут быть улучшены, например, комплексообразованием с $\gamma$-циклодекстрином, глицирризиновой кислотой и другими соединениями, способными образовывать комплексы включения за счет гидрофобного связывания [3, 6, 8, 10-12]. Наиболее простой и эффективный способ улучшения водорастворимости бетулина и некоторых его производных - это химическая модификация в соответствующие сульфаты. Сернокислотные эфиры бетулина, бетулиновой кислоты проявляют биологическую активность, и их рассматривают как перспективные ингибиторы для селективного подавления классического пути комплемента на максимально раннем уровне [12, 13].

Предложенные ранее методы сульфатирования тритерпеноидов основаны на использовании серной кислоты и комплексов, полученных при взаимодействии серного ангидрида с пиридином или диметилсульфоксидом [13, 14]. Так, синтез 3,28-дисульфата бетулина и 3-сульфата бетулиновой кислоты проводят сульфатированием бетулина и бетулиновой кислоты серной кислотой в пиридине в присутствии уксусного ангидрида [13].

Проведение сульфатирования тритерпеноидов хлорсульфоновой или сульфаминовой кислотой в среде таких слабых оснований, как диметилформамид или диоксан, может не только сопровождаться изомеризацией исходного бетулина [9], но сульфатированный тритерпеноид первоначально образуется в малостабильной Н-форме [15]. Известно, что комплекс $\mathrm{SO}_{3}-$ пиридин является более мягким сульфатирующим реагентом по сравнению с комплексом $\mathrm{SO}_{3}$ - 1,4-диоксан, атакует исключительно спиртовые группы и не затрагивает двойную связь, а комплекс $\mathrm{SO}_{3}-1,4$-диоксан может взаимодействовать со спиртовыми группами и атаковать двойную связь [16]. Применение при сульфатировании бетулина пиридина вместо 1,4-диок-

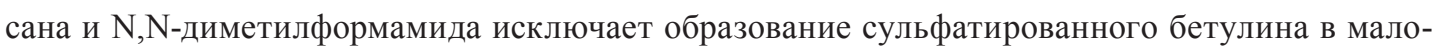
стабильной Н-форме [15], сульфатированный бетулин образуется в стабильной солевой форме.

С целью синтеза с высокой селективностью 3,28-дисульфата бетулина в стабильной солевой форме исследован процесс сульфатирования бетулина хлорсульфоновой кислотой в пиридине. Строение 3,28-дисульфата бетулина изучено методами ИК-, КР-, ЯМР-спектроскопии, электронной микроскопии. Способность натриевой соли 3,28-дисульфата бетулина к мицеллообразованию определена кондуктометрическим методом.

$$
-449-
$$




\section{Экспериментальная часть}

Бетулин, используемый для сульфатирования, получали по оригинальной методике, приведенной в работе [17].

Сульфатирование бетулина хлорсульфоновой кислотой в пиридине. В трехгорлую колбу вместимостью 100 мл, снабженную механической мешалкой, термометром и капельной воронкой, помещали 40 мл обезвоженного пиридина и прикапывали к нему при перемешивании и температуре $0-5{ }^{\circ} \mathrm{C} 2-5$ мл $(0,03-0,075$ моль) хлорсульфоновой кислоты. Полученный комплекс пиридина и триоксида серы нагревали до температуры $65{ }^{\circ} \mathrm{C}$ на глицериновой бане и присыпали к нему 4,42 г (0,01 моль) бетулина. Далее температуру реакционной смеси поднимали до $70^{\circ} \mathrm{C}$ и выдерживали при этой температуре в течение 2 ч. Затем реакционную смесь охлаждали до $10-15{ }^{\circ} \mathrm{C}$, разбавляли 30 мл воды и нейтрализовывали $10 \%$-ным водным раствором гидроксида натрия до $\mathrm{pH} \sim 9$. Раствор упаривали досуха под вакуумом водоструйного насоса. К твердому остатку добавляли 70 мл обезвоженного этанола и кипятили в течение 30 мин. Горячую смесь отфильтровывали, маточный раствор упаривали досуха под вакуумом водоструйного насоса. Выход твердого остатка, в состав которого входили смесь моно- и дисульфата бетулина или 3,28-дисульфат бетулина, 5,5-6,1 г. При проведении физико-химических исследований использовали перекристаллизованный из этанола 3,28-дисульфат бетулина.

Выделение пиридиниевой соли 3,28-дисульфата бетулина из реакционной массы проводили сразу по окончании процесса сульфатирования. Реакционную массу упаривали досуха под вакуумом водоструйного насоса. К твердому остатку добавляли 70 мл обезвоженного этанола и кипятили в течение 30 мин. Горячую смесь отфильтровывали, маточный раствор упаривали досуха под вакуумом. Твердый остаток представлял собой пиридиниевую соль 3,28-дисульфата бетулина. Выход 7,0- 7,1 г (92,1 - 93,4\%).

$\mathrm{H}^{+}$-Форму 3,28-дисульфата бетулина получали из натриевой соли дисульфата бетулина на катионите КУ-2-8 подобно методике, описанной в работе [18]. Предварительно ионообменную смолу КУ-2-8, вырабатываемую в промышленности в $\mathrm{Na}+$-форме, переводили в $\mathrm{H}^{+}$-форму. Для этого через слой смолы КУ-2-8 в Na+-форме, помещенной в виде гомогенной смеси с дистиллированной водой в вертикальную стеклянную колонку диаметром 15-20 мм, вместимостью 50 мл, снабженную внизу краном, пропускали водный $2 \mathrm{M}$ раствор $\mathrm{HCl}$ до равных концентраций поступающего и вытекающего из колонки раствора соляной кислоты. Затем промывали смолу дистиллированной водой до нейтральной реакции промывных вод по метиловому красному. Затем через слой подготовленного катионита пропускали раствор 1,0 г перекристаллизованной из этанола натриевой соли 3,28-дисульфата бетудина в 50 мл дистиллированной воды. После прохождения через колонку раствора натриевой соли дисульфата бетулина смолу в колонке промывали дистиллированной водой (3 раза по 20 мл). Собирали промывные жидкости и досуха упаривали раствор под вакуумом водоструйного насоса при температуре отгонки не более $40{ }^{\circ} \mathrm{C}$. Выход 0,8 г.

Растворители пиридин, этанол были очищены и обезвожены известными методами [19].

Контроль состава реакционной массы проводили методом тонкослойной хроматографии (TXC) на пластиках силуфола марки «Silufol» UV-254 по общепринятой методике [19]; в качестве меток использовали бетулин и аллобетулин; элюент: хлороформ-ацетон (1:15). Проявление хроматограммы проводили в плотно закрытой камере, насыщенной парами йода. 
ИК-спектры бетулина и 3,28-дисульфата бетулина снимали на Фурье-ИК-спектрометре фирмы Bruker в области длин волн 400-4000 $\mathrm{cm}^{-1}$. Образцы запрессовывали в матрицу $\mathrm{KBr}(3$ мг образца / 300 мг $\mathrm{KBr})$.

Спектры ЯМР ${ }^{13} \mathrm{C}$ сняты на спектрометре Bruker Avance III 600 МГц в дейтерометаноле с привязкой к дейтериевому резонансу растворителя.

Элементный анализ сульфатированных образцов осуществляли на элементном анализатоpe Flash EA-1112 (Thermo Quest Italia).

Электронные микрофотографии получены на растровом электронном микроскопе ТМ-1000 HITACHI (Япония) с ускоряющим напряжением $15 \mathrm{kV}$ и с увеличением от 100 до 10000 крат с разрешением 30 нм.

КР-спектры образцов были сняты на NXR FT-Raman модуле для ИК-Фурье-спектрометра Nicolet 6700 с охлаждаемым жидким азотом Ge диодом в качестве детектора. В качестве источника света для возбуждения рамановского рассеяния применяли $\mathrm{CW}-\mathrm{Nd}$ : YAG-лазер с возбуждающей линией 1,064 нм. КР-спектры были записаны в диапазоне 200-3500 см-1 с использованием рабочего спектрального разрешения $8 \mathrm{~cm}^{-1}$. Выходная мощность лазера составляла $100 \mathrm{~mW}$. Каждый образец был дважды проанализирован при одинаковых условиях, и было накоплено 400 разверток. Усредненный спектр был сформирован как окончательный спектр соответствующего образца, и выполнена векторная нормировка спектра. Интегрирование пиков осуществили с помощью операционного спектроскопического программного обеспечения OPUS Ver. 6.0 (Bruker Optik GmbH, Эттлинген Германия). Анализ данных был проведен с помощью OriginPro 7.0 (OriginLab Corporation, Массачусетс США) программного обеспечения OPUS Ver. 6.0 (Bruker Optik GmbH, Эттлинген Германия).

Исследование удельной электропроводности водных растворов 3,28-дисульфата бетулина проводили при температуре $20^{\circ} \mathrm{C}$. Путем измерения удельной электропроводности растворов различной концентрации (диапазон концентраций составлял $1,35 \cdot 10^{-5}-1,35 \cdot 10^{-2}$ моль/л) был построен график зависимости удельной электропроводности от отрицательного десятичного логарифма концентрации. Для измерения удельной электропроводности использовали кондуктометр «Кондуктометр METTLER TOLEDO».

\section{Результаты и обсуждение}

Функциональные группы в бетулине, которые могут подвергаться сульфатированию, первичная и вторичная гидроксильные группы, а также двойная связь в изопропенильной группе у пятичленного цикла. При выборе сульфатирующих реагентов агента с целью сохранения двойной связи следует избегать использования тех реагентов, применение которых может привести к нежелательным реакциям по двойной связи. Таким реагентом является комплекс серный ангидрид - пиридин $\left(\mathrm{SO}_{3} \cdot \mathrm{C}_{5} \mathrm{H}_{5} \mathrm{~N}\right)[16]$.

$\mathrm{B}$ качестве источника серного ангидрида при получении его комплексов с основаниями может использоваться хлорсульфоновая кислота. При взаимодействии хлорсульфоновой кислоты с пиридином при температуре $0-5{ }^{\circ} \mathrm{C}$ образуется комплекс $\mathrm{SO}_{3_{3}}-$ пиридин и пиридиний хлорид [16]:

$$
\begin{gathered}
\mathrm{ClSO}_{3} \mathrm{H}+2 \mathrm{C}_{5} \mathrm{H}_{5} \mathrm{~N} \rightarrow \mathrm{SO}_{3} \cdot \mathrm{C}_{5} \mathrm{H}_{5} \mathrm{~N}+\mathrm{C}_{5} \mathrm{H}_{5} \mathrm{~N} \cdot \mathrm{HCl} . \\
-451-
\end{gathered}
$$


Этот способ получения комплекса $\mathrm{SO}_{3} \cdot \mathrm{C}_{5} \mathrm{H}_{5} \mathrm{~N}$ весьма прост, реакция протекает почти количественно.

В работе исследовано влияние условий процесса сульфатирования бетулина хлорсульфоновой кислотой в пиридине на селективность образования 3,28-дисульфата бетулина в виде стабильной натриевой соли. С учетом слабой растворимости сульфатирующего комплекса в пиридине при комнатной температуре и его невысокой реакционной способности при температуре менее $55^{\circ} \mathrm{C}[16]$ сульфатирования бетулина проводили при температуре $70{ }^{\circ} \mathrm{C}$ в течение 2 ч. Исследование процесса сульфатировании бетулина осуществляли при различных мольных соотношениях реагентов бетулин : хлорсульфоновая кислота. Условия и результаты сульфатирования бетулина представлены в табл. 1.

Реакция сульфатирования бетулина хлорсульфоновой кислотой в пиридине включает стадии образования пиридиниевой соли 3,28 -дисульфата бетулина с ее последующей трансформацией в натриевую соль 3,28-дисульфата бетулина (рис. 1).

Из результатов исследования состава продуктов реакции методом тонкослойной хроматографии и содержания серы вытекает, что использование стехиометрического количества сульфатирующего агента приводит к образованию сульфатированного продукта без примеси бетулина, содержащего $40 \%$ мас. моносульфата и $60 \%$ мас. дисульфата бетулина. С ростом количества сульфатирующего агента количество дисульфата бетулина в составе сульфатированного продукта возрастает. При двухкратном и более избытке сульфатирующего агента 3,28-дисульфат бетулина образуется с селективностью 100\% и выходом 93-95\%. Образующийся 3,28-дисульфат бетулина был выделен в виде натриевой и пиридиниевой солей, которые являются гидролитически устойчивыми. Эти соли можно подвергать перекристаллизации из этанола, а их водные растворы имеют длительный срок хранения. Натриевая соль дисульфата бетулина была переведена в $\mathrm{H}^{+}$-форму методом ионного обмена на катионите КУ-2-8. Обнаружено, что $\mathrm{H}^{+}$-форма 3,28-дисульфата бетулина в водном растворе является гидролитически нестойким соединением. При непродолжительном нагревании ее водного раствора при температуре свыше $45^{\circ} \mathrm{C}$ осаждается твердый продукт, который растворяется в этиловом спирте. Методом тонкослойной хроматографии установлено, что не растворимый в воде твердый про-

Таблица 1. Влияние условий сульфатирования бетулина хлорсульфоновой кислотой в пиридине на содержание серы и выходмоносульфатабетулина (МСБ) и дисульфатабетулина (ДСБ)в сульфатированном продукте (СП*)

Table 1. Influence of conditions of betulin sulfation with chlorosulfonic acid in pyridine on sulfur content and yield of betulin monosulfate (MSB) and betulin disulfate (DSB) in sulfated product (SP *)

\begin{tabular}{|c|c|c|c|c|c|}
\hline \multirow{2}{*}{ № опыта } & \multirow{2}{*}{$\begin{array}{c}\text { Соотношение } \\
\text { бетулин:С1SO } \mathrm{H}, \\
\text { моль:моль }\end{array}$} & $\begin{array}{c}\text { Содержание } \\
\text { серы, \% }\end{array}$ & $\begin{array}{c}\text { Селективность по } \\
\text { ДСБ, \% }\end{array}$ & \multicolumn{2}{|c|}{ Выход, \% (мас.) } \\
\cline { 4 - 6 } & $1: 2$ & 8,13 & 60,0 & 36,7 & 55,0 \\
\hline 1 & $1: 3$ & 9,21 & 84,0 & 14,3 & 77,8 \\
\hline 3 & $1: 4,0$ & 10,06 & 100 & 0,0 & 94,6 \\
\hline 4 & $1: 5,0$ & 9,68 & 100 & 0,0 & 92,9 \\
\hline
\end{tabular}

*СП - сульфатированный продукт - смесь моно- и дисульфата бетулина. 


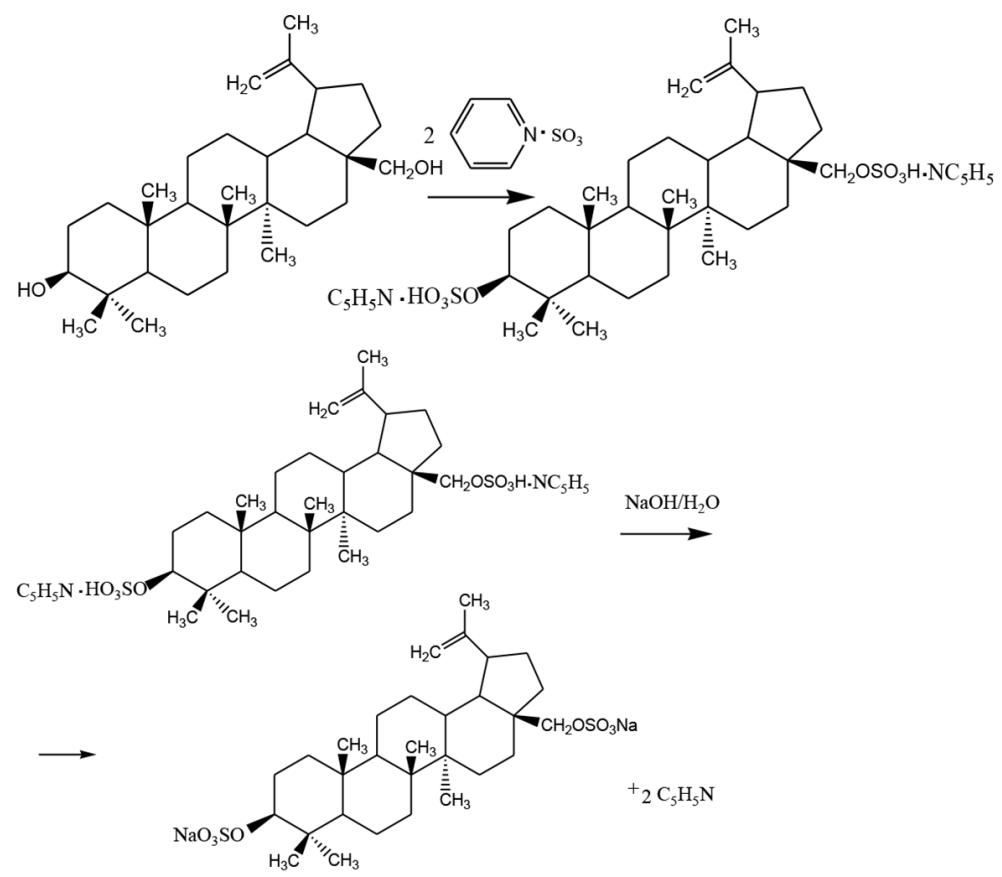

Рис. 1. Схема синтеза пиридиниевой и натриевой солей 3,28-дисульфата бетулина

Fig. 1. Scheme of synthesis of pyridinium and sodium salts of betulin 3,28-disulfate

дукт состоит из бетулина и аллобетулина. Таким образом, $\mathrm{H}^{+}$-форма 3,28-дисульфата бетулина при нагревании подвергается гидролизу с образованием бетулина, серной кислоты и аллобетулина - продукта изомеризации бетулина в кислой среде.

Состав 3,28-дисульфата бетулина в натриевой $\left(\mathrm{C}_{30} \mathrm{H}_{48} \mathrm{O}_{8} \mathrm{Na}_{2} \mathrm{~S}_{2}\right)$ и пиридиниевой $\left(\mathrm{C}_{40} \mathrm{H}_{60} \mathrm{O}_{8} \mathrm{~N}_{2} \mathrm{~S}_{2}\right)$ солевых формах подтвержден данными элементного анализа. Найдено (для натриевой соли), \%: С 56,10; Н 7,78; S 9,87. Вычислено (для натриевой соли), \%: С 55,72; Н 7,43; S 9,91. Найдено (для пиридиниевой соли), \%: С 63,88; Н 7,32; N 3,92; S 8,19. Вычислено (для пиридиниевой соли), \%: С 63,16; Н 7,89; N 3,68; S 8,42.

Строение 3,28-дисульфата бетулина в натриевой, пиридиниевой солевых формах и $\mathrm{H}^{+}$форме подтверждено данными ИК-спектроскопии (рис. 2). В ИК-спектре натриевой соли 3,28-дисульфата бетулина присутствуют интенсивная полоса асимметричных валентных колебаний vas $(\mathrm{O}=\mathrm{S}=\mathrm{O})$ при $1246 \mathrm{~cm}^{-1}$ и полоса поглощения валентных колебаний $v(\mathrm{C}-\mathrm{O}-\mathrm{S})$ [20-21] в области 833-840 cм-1. Полоса асимметричных валентных колебаний vas $(\mathrm{O}=\mathrm{S}=\mathrm{O})$ для пиридиниевой соли расположена в области $1251 \mathrm{~cm}^{-1}$, полоса поглощения, соответствующая валентным колебаниям $v(\mathrm{C}-\mathrm{O}-\mathrm{S})$ - в области 828-818 cм-1. Для $\mathrm{H}^{+}$-формы дисульфата бетулина полоса поглощения vas $(\mathrm{O}=\mathrm{S}=\mathrm{O})$ находится в области меньших частот при $1180 \mathrm{~cm}^{-1}[20,21]$, полоса поглощения $(\mathrm{C}-\mathrm{O}-\mathrm{S})$ трудно идентифицируется.

Введение сульфатной группы в структуру бетулина также подтверждается наличием в КРспектре натриевой соли 3,28-дисульфата бетулина полос поглощения в областях 1076, $1260 \mathrm{~cm}^{-1}$ (рис. 3). Полоса поглощения при $1076 \mathrm{~cm}^{-1}$ доминирует в спектре и соответствует симметричным валентным колебаниям vas $(\mathrm{O}=\mathrm{S}=\mathrm{O})$. Другая полоса поглощения при $1260 \mathrm{~cm}^{-1}$ относится 


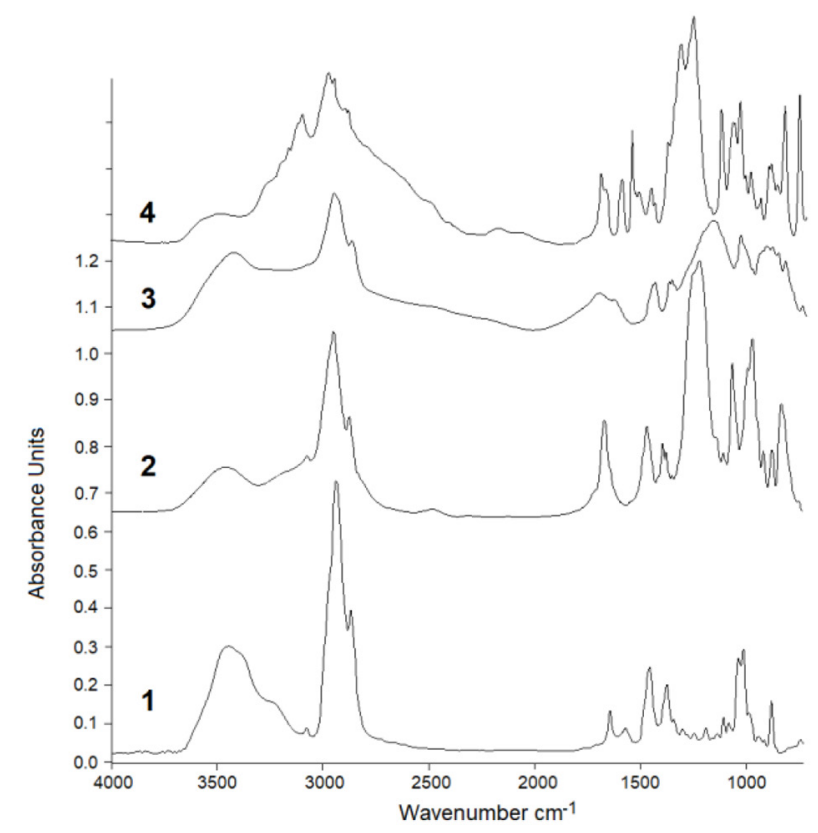

Рис. 2. ИК-спектры: 1 - бетулин; 2 - натриевая соль 3,28-дисульфата бетулина; 3 - $\mathrm{H}^{+}$-форма 3,28-дисульфата бетулина; 4 - пиридиниевая форма 3,28-дисульфата бетулина

Fig. 2. FTIR spectra: 1 - betulin; 2 - sodium salt of betulin 3,28-disulfate; 3 - $\mathrm{H}^{+}$-form of 3,28-disulfate of betulin disulfate; 4 - pyridinium form of 3,28-disulfate of betulin disulfate

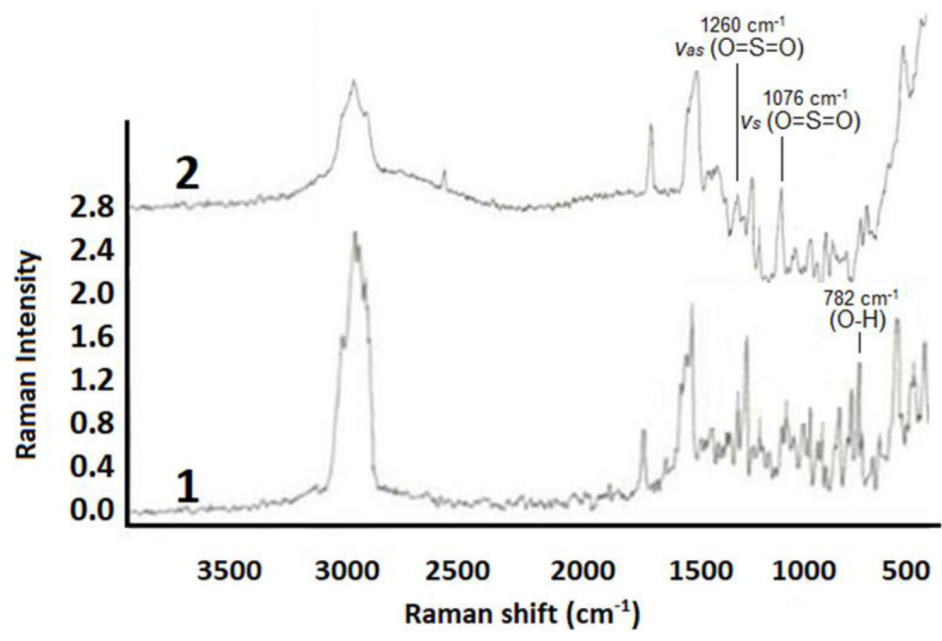

Рис. 3. КР-спектры: 1 - бетулин; 2 - натриевая соль 3,28-дисульфата бетулина

Fig. 3. Raman spectra: 1 - betulin; 2 - sodium salt of betulin 3,28-disulfate

к асимметричным валентным колебаниям vas $(\mathrm{O}=\mathrm{S}=\mathrm{O})$ [20-22]. Дополнительным подтверждением наличия сульфатной группы в образце является отсутствие в КР-спектре дисульфата бетулина по сравнению с КР-спектром бетулина полосы средней интенсивности при $782 \mathrm{~cm}^{-1}$, относящейся к колебаниям связи О-Н в $\mathrm{CH}_{2} \mathrm{OH}$ группе [23]. В КР-спектрах как бетулина, так 
и натриевой соли дисульфата бетулина присутствуют полосы поглощения, характерные для лупанового селета пентациклического тритерпеноида в областях 1642-1644, 1440-1448, 1190-

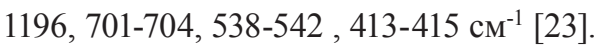

Состав и строение натриевой соли 3,28-дисульфата бетулина подтверждены также методом ЯМР ${ }^{13} \mathrm{C}$-спектроскопии. В соответствии с литературными данными [15] химический сдвиг вторичного атома углерода $\mathrm{C}_{3}$, связанного с гидроксильной группой, наблюдается при 78-79 м.д. группой, у первичного $\mathrm{C}_{28}$ - при 59-60 м.д. Анализ ЯМР ${ }^{13} \mathrm{C}$-спектров исходного бетулина и натриевой соли 3,28-дисульфата бетулина показал, что у исходного бетулина химический сдвиг атома углерода $\mathrm{C}_{3}$ наблюдается при 78,25 м.д. и атома углерода $\mathrm{C}_{28}$ при 58,96 м.д. В синтезированном 3,28 -дисульфате бетулина химические сдвиги углеродов $\mathrm{C}_{3}$ и $\mathrm{C}_{28}$ по сравнению с бетулином полностью смещены в область слабого поля, соответственно к 88,25 и 67,33 м.д. Это доказывает полное замещение гидрокильных групп бетулина на сульфатные группы.

Методом растровой электронной микроскопии (РЭМ) изучена морфология образцов натриевой соли дисульфата бетулина и бетулина (рис. 4 и 5). Бетулин состоит из частиц игольчатой формы, размер которых варьируется от 0,3 до 1 мкм. Некоторые частицы собраны в агрегаты длиной 20-40 мкм.

Как следует из рис. 4, образец натриевой соли 3,28-дисульфата бетулина имеет морфологию, отличную от морфологии образца бетулина. Он состоит из игольчатых кристаллов, собранных в агрегаты паутинообразной формы, минимальный размер которых составляет 200 мкм.

Водный раствор натриевой соли дисульфата бетулина при низких концентрациях представляет собой прозрачный раствор, при более высоких концентрациях наблюдается опалесценция. Это связано со способностью натриевой соли дисульфата бетулина к мицеллообразованию. Дифильное строение 3,28-дисульфат: наличие гидрофильной сульфатной группы и гидрофобной (олеофильной) пентациклической углеводородной части, обуславливает его способность к мицеллообразованию и проявлению поверхностно-активных свойств. Известно, что тритерпеновые сапонины [24], производные олеаноловой кислоты, как и другие природные органические вещества, не только проявляют достаточно широкий спектр фармакологической

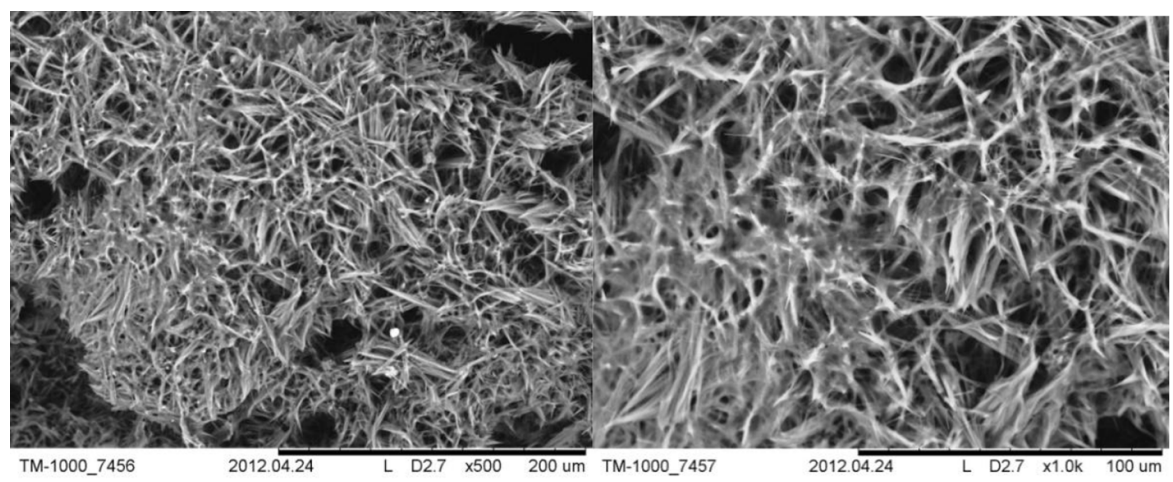

Рис. 4. Микрофотографии образца натриевой соли 3,28 дисульфата бетулина

Fig. 4. Micrographs of a sample of sodium salt 3.28 betulin disulfate

$$
-455-
$$




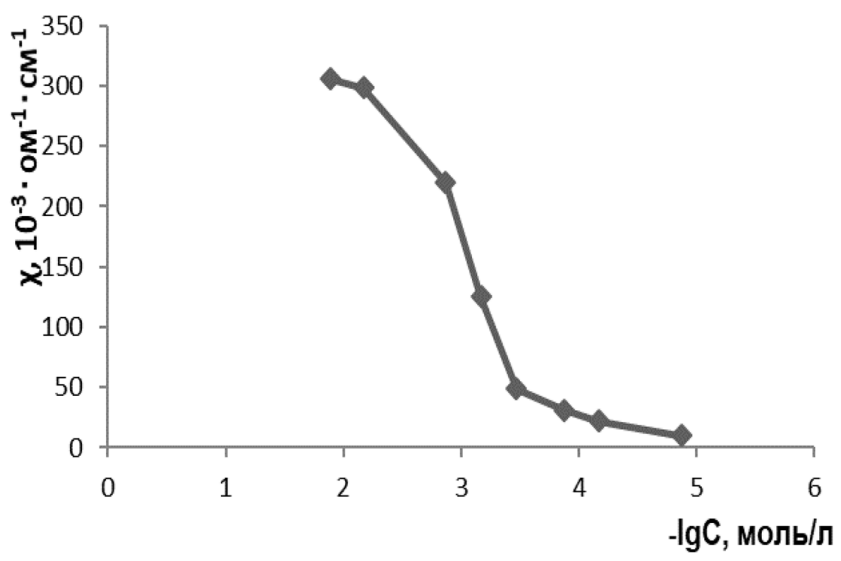

Рис. 5. Зависимость удельной электропроводности 3,28-дисульфата бетулина от $\lg$, моль/л

Fig. 5. Dependence of the specific electrical conductivity of 3,28-betulin disulfate on $\operatorname{lgC}, \mathrm{mol} / 1$

активности, входят в состав ряда лекарственных средств и биологически активных добавок, но и, обладая поверхностно-активными свойствами, используются в фармации и лечебной косметологии в качестве вспомогательных веществ (солюбилизаторов) [25-28]. Отличительной особенностью коллоидных ПАВ является способность образовывать термодинамически устойчивые (лиофильные) гетерогенные дисперсные системы - мицеллярные коллоиды после превышения некоторой характерной для каждого данного ПАВ концентрации, называемой критической концентрацией мицеллообразования (ККМ) $[25,26]$. Методы определения ККМ основаны на резком изменении физико-химических свойств растворов ПАВ (поверхностного натяжения, мутности, удельной электропроводности $(\chi)$, показателя преломления, осмотического давления) при переходе от молекулярного раствора к мицеллярному [25-28]. Для оценки принадлежности 3,28-дисульфата бетулина к коллоидным поверхностно-активным веществам (ПАВ) нами была определена критическая концентрация мицеллообразования. Для определения ККМ использован кондуктометрический метод. Известно, что при концентрации, соответствующей ККМ, на графике электропроводность - концентрация наблюдается излом, обусловленный образованием сферических ионных мицелл. Причиной снижения элекропроводности может быть не только меньшая подвижность мицелл, но и закрепление части противоионов тока на заряженной поверхности образующихся агломератов $[25,26]$. На рис. 5 представлены результаты измерения электропроводности водных растворов 3,28-дисульфата бетулина различной концентрации.

Зависимость, характерная для ПАВ, наблюдается и при измерении электропроводности дисульфата бетулина. До ККМ (в данном случае 0,23 ммоль/л) электропроводность растворов дисульфата бетулина нарастает с концентрацией. После точки излома нарастание электропроводности с концентрацией замедляется. По излому кривой, представленной на рис. 5 , значение ККМ составило 0,23 ммоль/л. Для сравнения: ККМ тритерпеновых сапонинов равно 0,65 ммоль/л [24]. 


\section{Заключение}

Предложено использовать сульфатирование бетулина хлорсульфоновой кислотой в среде пиридина для получения стабильной формы 3,28-дисульфата бетулина в виде пиридиниевой и натриевой солей.

Полная этерификация бетулина до 3,28-дисульфата достигается при температуре $70{ }^{\circ} \mathrm{C}$ в течение 2 ч при использовании двухкратного и более избытка сульфатирующего агента. Строение и состав 3,28-дисульфата бетулина подтверждено данными элементного анализа, тонкослойной хроматографии, ИК-, КР- и ЯМР ${ }^{13} \mathrm{C}-$ спектроскопии.

По данным РЭМ, натриевая соль 3,28-дисульфата бетулина представляет собой игольчатые кристаллы, собранные в агрегаты паутинообразной формы размером 200 мкм и более.

Установлено, что $\mathrm{H}^{+}$- форма 3,28-дисульфата бетулина в водном растворе является неустойчивой и гидролизуется до бетулина, который в кислой среде частично изомеризуется с образованием аллобетулина.

Натриевая соль 3,28-дисульфата обладает мицеллярными свойствами, значение критической концентрации мицеллообразования составляет 0,23 ммоль/л. Способность 3,28-дисульфата бетулина к мицеллообразованию обуславливает возможность его использования не только в качестве самостоятельного лекарственного средства, но и как стабилизатора лекарственных форм и солюбилизатора, повышающего растворимость трудно растворимых биологически активных веществ.

\section{Благодарности /Acknowledgments}

Работа выполнена в рамках государственного задания Института химии и химической технологии СО РАН (Проект ААAА-A17-117021310218-7) (V.46.4.3). В работе использованы приборы Красноярского регионального центра коллективного пользования СО РАН.

This work was performed within the framework of the state assignment of the Institute of Chemistry and Chemical Technology of the Siberian Branch of the Russian Academy of Sciences (Project AAAA-A17-117021310218-7) (V.46.4.3). The instruments of the Krasnoyarsk Regional Center for Collective Use of the SB RAS were used in the work.

\section{Список литературы / References}

1. Ashour M., Wink M., Gershenzon J. Biochemistry of terpenoids: monote rpenes, sesquiterpenes and diterpenes. Ann. Plant Rev. 2010. Vol. 40, P. 258-303.

2. Šiman P., Filipová A., Tichá A., Niang M., Bezrouk A., Havelek R. Effective Method of Purification of Betulin from Birch Bark: The Importance of Its Purity for Scientific and Medicinal Use. Plos One 2016. Vol. 11(5), P. 1-14.

3. Воробьева О.А., Малыгина Д.С., Грубова Е.В., Мельникова Н.Б. Производные бетулина. Биологиологическая активность и повышение растворимости. Химия растительного сырья. 2019. № 4. C. 407-430. [Vorobyova O. A., Malygina D. S., Grubova E. V., Melnikova N. B. Derivatives of betulin. Biological activity and increased solubility. Chemistry of plant raw material. 2019. Vol. 4, P. 407-430. (In Russ.)]

4. Hordyjewska A., Ostapiuk A., Horecka A., Kurzepa J. Betulin and betulinic acid: triterpenoids derivatives with a powerful biological potential. Phytochemistry Reviews 2019. Vol. 18, P. 929-951.

$$
-457-
$$


5. Tolstikov G.A., Flekhter O.B., Shultz E.E., Baltina L.A., Tolstikov A.G. Betulin and Its Derivatives. Chemistry and Biological Activity. Chem. Sustain. Develop. 2005. Vol. 13, P. 1-29.

6. Amiria S., Dastghaib S., Ahmadic M., Mehrbod P., Khademe F., Behroujb H., Aghanoorif M.-R., Machajg F., Ghamsaric M., Rosikg J., Hudeckih A., Afkhamic A., Hashemii M., Losjk M.J., Mokarramb P., Madrakianc T., S. Ghavamia. Betulin and its derivatives as novel compounds with different pharmacological effects. Biotechnology Advances. 2020. Vol. 38, 107409.

7. Sami A., Taru M., Salme K., Jari Y.-K. Pharmacological properties of the ubiquitous natural product botulin. European Journal of Pharmaceutical Sciences. 2006. Vol. 29 (1), P. 1-13.

8. Król S. K., Kiebus M., Rivero-Müller A., Stepulak A. Comprehensive Review on Betulin as a Potent Anticancer Agent. BioMed Research International. 2015, 584189,

13. Heidary Navid M., Laszczyk-Lauer M.N., Reichling J., Schnitzler P. Pentacyclic triterpenes in birch bark extract inhibit early step of herpes simplex virus type 1 replication. Phytomedicine. 2014. Vol. 21(11), P. 1273-1280.

9. Dehaen W., Mashentseva A. A., Seitembetov T. S.. Allobetulin and Its Derivatives: Synthesis and Biological Activity. Molecules 2011. Vol. 16, P. 2443-2466.

10. Wang H.M., Soica C., Wenz G. A Comparison Investigation on the Solubilization of Betulin and Betulinic Acid in Cyclodextrin Derivatives. Natural product communications. 2012. Vol. 3(7), P. 289.

11. Şoica C., Dehelean C., Danciu C., Wang H. M., Wenz G., Ambrus R., Bojin F., Anghel M. Betulin Complex in $\gamma$-Cyclodextrin Derivatives: Properties and Antineoplasic Activities in In Vitro and In Vivo Tumor Models. International Journal of Molecular Sciences. 2012. Vol. 13(11), P. 14992-15011.

12. Vorobyova O., Deryabina O., Malygina D., Plotnikova N., Solovyeva A., Belyaeva K., Melnikova N. Betulin-3,28-diphosphate as a Component of Combination Cytostatic Drugs for the Treatment of Ehrlich Ascites Carcinoma In Vitro and In Vivo Experiments. Journals Sci. Pharm. 2018. Vol. 86(2), P. 1-14.

13. Bureeva S., Andia-Pravdiva J., Symon A., Bichucher A., Moskaleva V., Popenko V., Shpak A., Shvets V., Kozlov L., Kaplun A. Selective inhibition of the interaction of Clq with immunoglobulins and the classical pathway of complement activation by steroids and triterpenoids sulfates. Bioorganic \& Medicinal Chemistry. 2007. Vol. 15, P. 3489-3498.

14. Grishkovets V. I. Synthesis of triterpenoid sulfates using the $\mathrm{S}_{3}$-dimethylsulfoxide complex. Chemistry of Natural Compounds. 1999. Vol. 1, P. 91-93.

15. Levdanskii V. A., Levdanskii A. V., Kuznetsov B. N. Sulfation of betulin by sulfamic acid in dmf and dioxane. Chemistry of Natural Compounds. 2014. Vol. 50(6), P. 1029-1031

16. Джильберт Э.Е. Сульфирование органических соединений. М.: Химия, 1969. 416 с. Пер. с англ. [Dzhil'bert E.E. Sulfonation of organic compounds. Moscow, 1969. 416 p. (In Russ.)].

17. RU 234000624. Способ получения бетулина / В.А. Левданский, А.В. Левданский, Б.Н. Кузнецов; Опубл. 10.12.2008. - С. 1-8.] [RU 234000624. A method for producing betulin / V.A. Levdansky, A.V. Levdansky, B.N. Kuznetsov; Publ. 10.12.2008. - P. 1-8. (in Russ.)]

18. Vasilyeva N.Yu., Levdansky A.V., Kazachenko A.S., Skvortsova G.P., Kuznetsov B.N. Modification of Sulfated Arabinogalactan with Amino Acids by Ion Exchange Method. Journal of Siberian Federal University. Chemistry. 2016. Vol. 9(1), P. 20-28. 
19. Гордон А., Форд Р. Спутник химика. М: Мир, 1976. 541 с. [Gordon A., Ford R. Sputnik khimika. Chemist's satellite. Moscow, 1976, 541 p. (in Russ.)].

20. F. Cabassi, B. Casu, A. S. Perlin. Infrared absorption and Raman scattering of sulfate groups of heparin and related glycosaminoglycans in aqueous solution. Carbohydrate Research. 1978. Vol. 63, P. 1-11.

21. Rohowsky J., Heise K., Fischer S., Hettrich K., Rohowsky J. Synthesis and characterization of novel cellulose ether sulfates. Carbohydrate Polymers. 2016. Vol. 142, P. 56-62.

22. Matsuhiro B., Osorio-Román I. O., Torres R.. Vibrational spectroscopy characterization and anticoagulant activity of a sulfated polysaccharide from sea cucumber Athyonidium chilensis. Carbohydrate Polymers. 2012. Vol. 88(3), P. 959-965.

23. Falamas A., Pınzaru S. C., Dehelean C. A., Peev C. I., Soica C. Betulin and its natural resourceas potential anticancer drug candidate seen by FT-Raman and FT-IR spectroscopy J. Raman Spectrosc. 2011. Vol. 42, P. 97-107.

24. Мироненко И. В., Брежнева Т. А., Пояркова Т. Н., Селеменев В. Ф. Определение некоторых поверхностно-активных характеристик растворов тритерпеновых сапонинов - производных олеаноловой кислоты. Химико-фармацевтичесий журнал. 2010. Том 44, №3, С. 24-51. [Mironenko I.V., Brezhneva T.A., Poyarkova T.N., Selemenev V.F. Determination of some surfaceactive characteristics of solutions of triterpene saponins - derivatives of oleanolic acid. Pharmaceutical Chemistry Journal. 2010. Vol. 44(3), P. 24-51. (in Russ.)].

25. Lange K. R.. Surfactants A Practical Handbook. Edited by: K. Robert Lange Hanser Publishers, Munich Hanser Gardner Publications, Inc., Cincinnati . 1999 by Carl Hanser Verlag, Munich/FRG.

26. Гельфман М. И., Ковалевич О. В., Юстратов В. П., Коллоид. химия. Лань, СанктПетербург. 2005. - 336 с. [Gelfman M.I., Kovalevich O.V., Yustratov V.P., Colloid. chemistry. Lan, St. Petersburg. 2005. - 336 p. (in Russ.)]

27. Edbey K., Bader N., Eltaboni1 F. B., Imragaa A., Albaba S., Ahmed M. Conductometric and Spectrophotometric Study of the Interaction of Methyl Violet with Sodium Dodecyl Sulfate. International Research Journal of Pure \& Applied Chemistry. 2015. Vol. 9(4), P. 1-7.

28. Кириченко Е.Е., Сычев И.А., Чекулаев Г.Ю. Выделение, физико-химическое исследование и определение солюбилизирующей активности полисахаридов цветков пижмы обыкновенной. Российский медико-биологический вестник имени академика И.П. Павлова. 2012. №4б C. 146-149. [Kirichenko E.E., Sychev I.A., Chekulaev G.Yu. Isolation, physicochemical study and determination of the solubilizing activity of polysaccharides in the flowers of common tansy. Russian medical and biological bulletin named after academician I.P. Pavlova. 2012. Vol. 4. P. 146-149. (in Russ.)]. 